\title{
Interactive comment on "Seasonal effects of photophysiology and chlorophyll a abundance on phytoplankton group-specific primary production in the Kuroshio region as revealed by SeaStar/SeaWiFS" by Takafumi Hirata and Koji Suzuki
}

\section{Anonymous Referee \#1}

Received and published: 27 June 2017

Because different phytoplankton has different response to light and nutrients, it is always desired to know group (or class or species) specific photosynthesis rate, as such information can also improve the estimation of global primary production. To meet this desire and demand, the authors developed specific primary production in the Kuroshio region for three "functional groups" of phytoplankton: diatoms, haptophytes, and cyanobacteria. Subsequently, the authors described their spatial/temporal variations as well as the possible driving factors. This subject is appropriate for the journal

Printer-friendly version

Discussion paper 
and the overall presentation is very good. However, there are serious gaps in this work. Specifically, as the authors indicated, to derive group-specific primary production, it requires 1) Chla, 2) aph, 3) PP, and 4) PAR. Because of lacking or no concurrent measurements of these properties, the authors used products in the Kuroshio region generated by NASA or a not commonly used algorithm for aph510 (see Section 2.1.2)! Note that the algorithms for Chla and PP were designed for global mean states, which very likely don't work for this specific (and unique) region (see the wide scatters for the Chla and PP algorithms). Thus, it is critical to evaluate these products derived from satellite for a specific region! But the authors spent no time to do so or to inform the validity of these products in the Kuroshio region. Without such, the group-specific primary production derived from these products are highly questionable to be the least.

In addition, Eq. 1, which plays a key role in this study, is unclear in many ways: 1) Not clear if it is for water-column integrated PP or PP at a specific depth. If it is watercolumn integrated PP, it is then not proportional to $E$ (e.g., VGPM); if it is PP at a depth, then phi, E, and aph should be in general a function of depth. 2) After the oversimplification (and not proven), the right side of the equation is a spectrum (wavelength dependent), but the left side is a scalar. The two sides are not consistent!

In view of the above, I don't think this work is publishableiijN at least in its current form.

Interactive comment on Biogeosciences Discuss., https://doi.org/10.5194/bg-2017-164, 2017. 